\title{
Experimental Analysis of Punch SPEed IMPACT ON Plastic BEHAVIOUR OF EXTRUDED MATERIAL
}

\author{
GUSEL, L.
}

Abstract: The knowledge of plastic behaviour of formed material, especially in critical regions of deformed zone and its dependence on different forming parameters, is very important to avoid failures, e.g. cracks in the final product and to increase efficiency of forming process. The visioplasticity method was applied in this paper for analysing the impact of punch speed on strain rate and stress distribution in cold direct extruded alloy. This method provides accurate information about material flow with the help of experimentally determined velocity field displacements. Different values of punch speed were used during direct extrusion experiments. Strain rate distributions and radial stress values in deformed zone were calculated and analysed. The results obtained by visioplasticity method have shown that higher punch speed has significant impact on increasing strain rate and stress values especially in some critical areas of deformed zone.

Key words: Metal forming, visioplasticity, punch speed, strain rate, stress


Authors' data: Assist. Prof. Dr. Gusel, L[reo]; University of Maribor, Faculty of Mechanical Engineering, Smetanova 17, 2000, Maribor, Slovenia, leo.gusel@um.si

This Publication has to be referred as: Gusel, L[eo] (2018). Experimental Analysis of Punch Speed Impact on Plastic Behaviour of Extruded Material, Chapter 06 in DAAAM International Scientific Book 2018, pp.065-074, B. Katalinic (Ed.), Published by DAAAM International, ISBN 978-3-902734-19-8, ISSN 1726-9687, Vienna, Austria

DOI: $10.2507 /$ daaam.scibook.2018.06 


\section{Introduction}

Extrusion processes have become one of the most extended manufacturing processes used in the mass production of different products in automotive and other industry because of high material savings, good surface quality, size accuracy of final products and also high productivity. The process is influenced by different parameters such as mechanical properties of the material to be formed, shape and quality of forming tool, kinematics and stiffness of machine, lubrication, temperature, punch speed and others. To produce high quality products by extrusion material characteristics, strain, strain rate and stress fields in the plastic zone of deformed material must be investigated. In modern metal forming industry there is a great emphasis on increasing productivity which can be achieved for example by using better tools (Ojo et al., 2015), new machines, good lubrication and also by applying higher punch speed in forming process. Punch speed also has important influence on tool wear, material flow and plastic behaviour in deformed zone, mechanical and other properties of the formed parts. Knowing the distribution of strain rates, strains and stresses in the plastic zone of extruded material at different punch speeds is very important for product quality prediction. With higher speed the danger of cracks in critical areas of formed zone increases. The ability to predict the critical zones for defects in the product would allow early modification of the process parameters and also reduce the risk of cracks forming (Dwivedi et al., 2013).

Although the theory of plasticity provides a great number of independent equations for defining the mechanism of plastic deformation it is very hard to obtain the exact analytical solution during metal forming. The mathematical modelling for process simulation has therefore become a major tool for analysis of metal forming processes. The majority of analysis in researches are based on finite elements method (Farhoumand \& Ebrahimi, 2016; Raja Satish et al., 2017; Trzepiecinski et al., 2017). Modelling of plastic behaviour in extrusion process and influence of die angle on strain rate is described in (Tolcha, 2014) while researchers in (Marin et al.,2013) analysed strain-stress relations in compressive forming process. In paper (Garcia-Dominguez et al., 2015) finite elements method for analysing the deformation parameters and friction load contributions in extrusion process was used. Plastic strain distributions and pressures are investigated in (Ilie et al., 2007) to predict the risk of cracks in the extruded material.

The visioplasticity method, which is more time consuming but provides the most realistic solutions, was applied in some research papers to determine stress state (Wang et. al, 1997) and deformation force in forming of Al alloy (Janjic et al., 2016) where the visioplasticity model of the stress field showed good accuracy with experimental results. In research (Gusel \& Rudolf, 2015) the impact of lubrication on shear stress distribution in extruded material was analysed while in paper (Jawad et al., 2012) authors successfully applied visioplasticity for measuring strains during extrusion process.

In this paper, the strain rate distribution as a function of punch speed and its influence on stress concentration in some critical areas in plastic zone of cold extruded CW106C alloy were analysed by applying the visioplasticity method. 


\section{Visioplasticity method}

Visioplasticity method is an experimental-theoretical method for analysis of strain, stress and strain rate distributions in plastic zone in axial-symmetric and plane processes based on measured velocity field points displacement. Basic equations of the plasticity theory are used in this method, such as balance equations and plastic flow conditions. The velocity vectors must be obtained experimentally by comparison of deformed and non-deformed mesh patterns. This method is very useful for the study of metal forming processes due to exact solutions in engineering sense but also has its limitation, such as possible errors in measurements of deformed mesh points, sensibility on mesh density and mesh lines quality and the method is time consuming. The mesh is usually inscribed on the specimen by pressing, etching, photo methods, etc. The quality of mesh lines is very important for the accuracy of the method therefore they should be thin and sharp.

For flow problems in which the flow field does not vary with respect to time, flow function $\theta$ can be used by measuring the points coordinates along the mesh lines. In axial-symmetric problems, the velocity field with axial $(\mathrm{z})$ and radial (r) velocity component can be written with the flow function $\theta(r, z)$ :

$$
v_{z}=\frac{1}{r} \frac{\partial \theta}{\partial r} \quad ; \quad v_{r}=\frac{1}{r} \frac{\partial \theta}{\partial z}
$$

\section{1. Strain rate and stress components calculation}

By knowing both velocity components in several points of the plastic zone, components of strain rate can be calculated (Lange, 1994):

$$
\dot{\varepsilon_{r}}=\frac{\partial v_{r}}{\partial r} ; \quad \dot{\varepsilon_{\vartheta}}=\frac{v_{r}}{r} ; \quad \dot{\varepsilon_{z}}=\frac{\partial v_{z}}{\partial z} ; \quad \dot{\varepsilon_{r z}}=\frac{1}{2}\left(\frac{\partial v_{r}}{\partial z}+\frac{\partial v_{z}}{\partial r}\right)
$$

The effective strain rate can be obtained from:

$$
\dot{\varepsilon_{e}}=\sqrt{\left(\frac{2}{3}\left(\dot{\varepsilon}_{r}^{2}+\dot{\varepsilon}_{\vartheta}^{2}+\dot{\varepsilon}_{z}^{2}+2 \dot{\varepsilon}_{r z}^{2}\right)\right)}
$$

The effective strain is calculated by:

$$
\varepsilon_{e}=\int_{0}^{t_{1}} \dot{\varepsilon_{e}} d t
$$

Strain rate components in axial, radial and shear directions are: 
Gusel, L.: Experimental Analysis of Punch Speed Impact on Plastic Behaviour of E...

$$
\begin{aligned}
& \dot{\varepsilon_{r}}=\lambda\left(\sigma_{r}-\sigma_{m}\right) \\
& \dot{\varepsilon_{z}}=\lambda\left(\sigma_{z}-\sigma_{m}\right) \\
& \dot{\varepsilon_{\vartheta}}=\lambda\left(\sigma_{\vartheta}-\sigma_{m}\right) \\
& \dot{\varepsilon}_{r z}=\lambda \tau_{r z}
\end{aligned}
$$

where $\mathbf{s}_{m}$ is medium stress while $\mathbf{I}$ is proportionality coefficient. Stress component in radial direction can be obtained from:

$$
\sigma_{r}=\int_{z_{0}}^{z_{1}}\left[\frac{\partial}{\partial z}\left(\frac{\dot{\varepsilon}_{r}-\dot{\varepsilon}_{z}}{\lambda}\right)-\frac{\partial}{\partial r}\left(\frac{\dot{\varepsilon}_{r z}}{\lambda}\right)-\frac{\dot{\varepsilon}_{r}}{\lambda r}\right] d z
$$

\section{Experimental details}

The main goal of the experiments was determination and analysis of the impact of punch speed on strain rate and stress distribution in plastic zone of deformed alloy. CW106C copper alloy cylinders with dimensions $32 \mathrm{~mm}$ x $\Phi 22 \mathrm{~mm}$ were used as test specimens for cold direct extrusion. These specimens were split into two equal half parts. On one half-part square mesh with $1 \mathrm{~mm}$ distance between mesh points was scribed by the $\mathrm{NC}$ milling machine for measuring the material flow during the extrusion process. Then two half parts were put together and cold extruded in a direct extrusion tool (Fig.1) on the hydraulic press. The load and displacement sensors were used for measuring the extrusion force. Limitation of our research were that the punch speed values were only possible up to $22 \mathrm{~mm} / \mathrm{s}$ due to capability of hydraulic press, we used only one lubricator and one material for specimens and didn't change the cone angle of the die or temperature of extrusion. The experiments were performed at room temperature. The die angle was $2 \alpha=45^{\circ}$ and coefficient of friction was $\mu=0,05$ in all experiments. Friction coefficient of lubricator was obtained by the standard ring test.



Fig. 1. Extrusion tool (left) and deformed mesh after extrusion (right). 
Four different values of punch speed $(8 \mathrm{~mm} / \mathrm{s}, 12 \mathrm{~mm} / \mathrm{s}, 16 \mathrm{~mm} / \mathrm{s}$ and $22 \mathrm{~mm} / \mathrm{s})$ were used during the extrusion experiments. After the extrusion the test specimens were taken out from the tool and the deformed mesh was measured by microscope for plasticity analysis. The deformed mesh of the specimen after direct extrusion is shown in Fig.1.

\section{Results and discussion}

With the help of measuring microscope, the position of every nodal point in the deformed mesh of direct extruded specimen was measured. Values of un-deformed mesh nodal points before extrusion, deformed mesh nodal points after extrusion, distances between un-deformed mesh points, flow curve and punch speed values were inserted and then compared and evaluated by visioplasticity computer program, which was developed in our laboratory. With determination of the difference between undeformed and deformed nodal mesh points the calculation of the velocities in several mesh nodal points in axial and radial directions was performed with the program. The local strain rate and stress values in several mesh points can be calculated from equations (2) to (9). The obtained strain rate components distributions in axial, radial and shear direction in the plastic zone of specimens extruded with four different punch speeds are shown in Fig. 2. to Fig. 4.

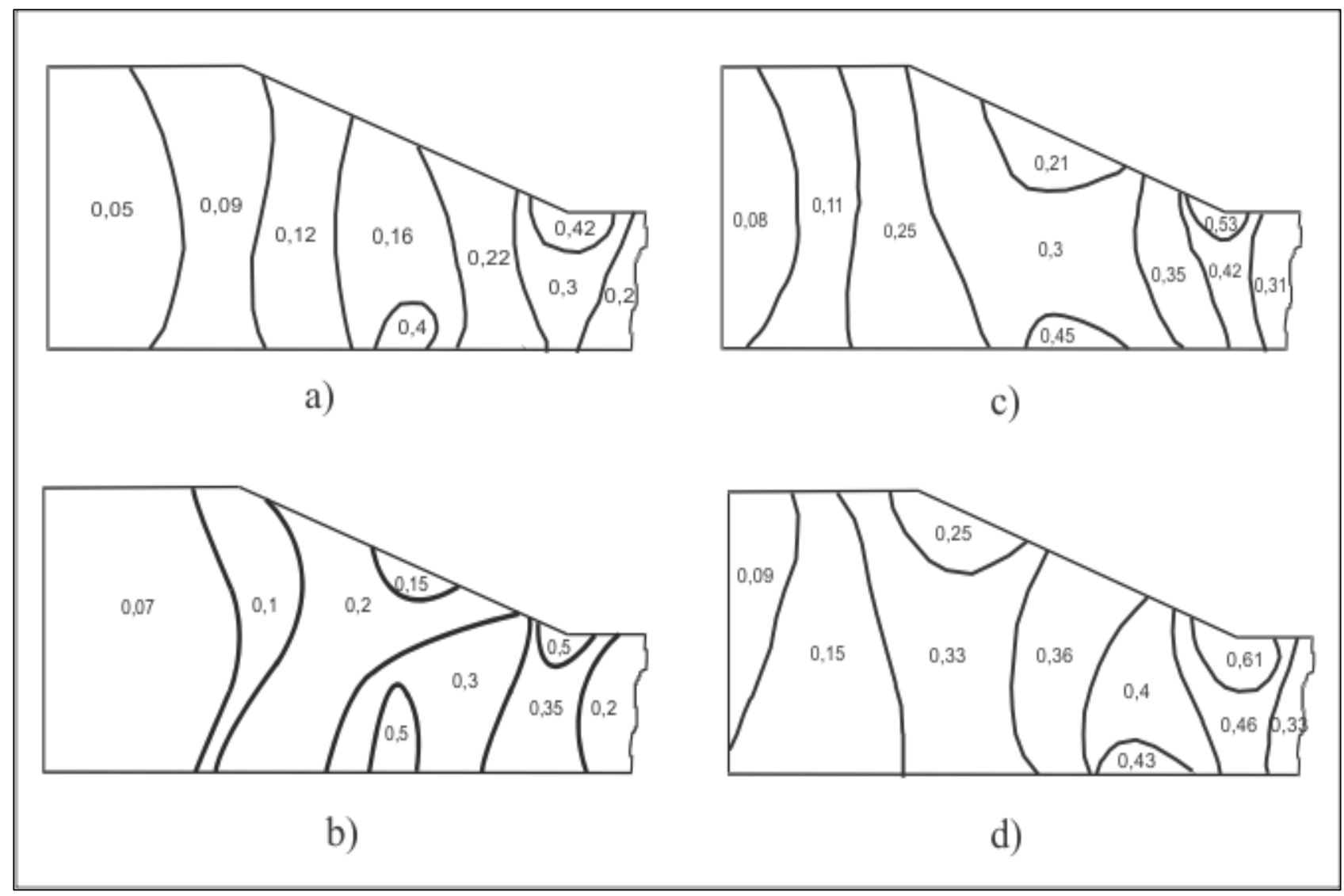

Fig. 2. Axial strain rate $\left(\dot{\varepsilon}_{\mathrm{z}}\right)$ distribution in plastic zone $\left[\mathrm{s}^{-1}\right](\mu=0,05)$ :
a) punch speed $v_{\mathrm{p}}=8 \mathrm{~mm} / \mathrm{s}$
c) punch speed $v_{\mathrm{p}}=16 \mathrm{~mm} / \mathrm{s}$
b) punch speed $v_{\mathrm{p}}=12 \mathrm{~mm} / \mathrm{s}$
d) punch speed $v_{\mathrm{p}}=22 \mathrm{~mm} / \mathrm{s}$ 
The influence of punch speed on axial strain rate distribution is presented in Fig. 2. It is obvious that the distribution increases quite uniform from the entrance of the plastic zone to the exit when extrusion with the lowest punch speed $\left(v_{\mathrm{p}}=8 \mathrm{~mm} / \mathrm{s}\right)$ was performed. Two small strain rate peaks can be observed, one in the central area along middle axis and one in the outer edge at the exit of the plastic zone. When higher punch speed was used the strain rate values increase and distribution become more dynamic but the position of two peak areas in the deformation zone didn't change much. The highest value for axial strain rate was always obtained at the exit of the deformed zone and was $50 \%$ higher when $v_{\mathrm{p}}=22 \mathrm{~mm} / \mathrm{s}$ was used compared to values at $v_{\mathrm{p}}=8 \mathrm{~mm} / \mathrm{s}$.

Radial strain rate distribution in deformed zone is shown in Fig. 3. It can be observed that as the punch speed increases, the values of the strain rate in the same areas of deformed zone increase and the extent of the peak area (outer part of the plastic zone) increases even faster. The values of strain rates in these peak areas and also at the end of the formed zone have more than doubled. The greatest difference was found out in the outer edge of the middle cone zone where values have increased from $\dot{\varepsilon}_{\mathrm{z}}=$ $0,12\left(v_{\mathrm{p}}=8 \mathrm{~mm} / \mathrm{s}\right)$ to $\varepsilon_{\mathrm{z}}=0,3$ when $\left.v_{\mathrm{p}}=22 \mathrm{~mm} / \mathrm{s}\right)$. Another interesting observation is a large area across the deformed zone with nearly constant strain rates values (Fig. 3(b) to Fig. 3(d)).

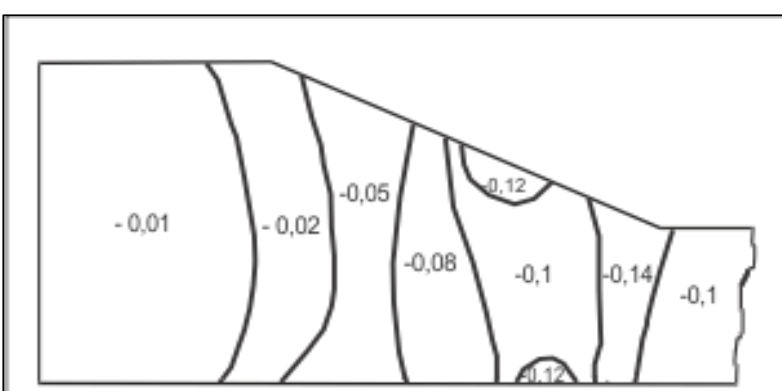

a)

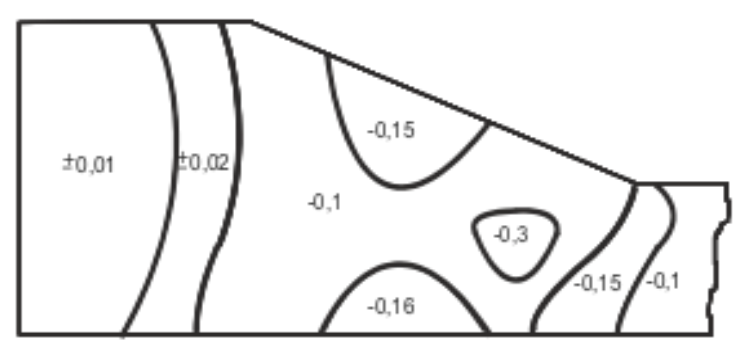

b)

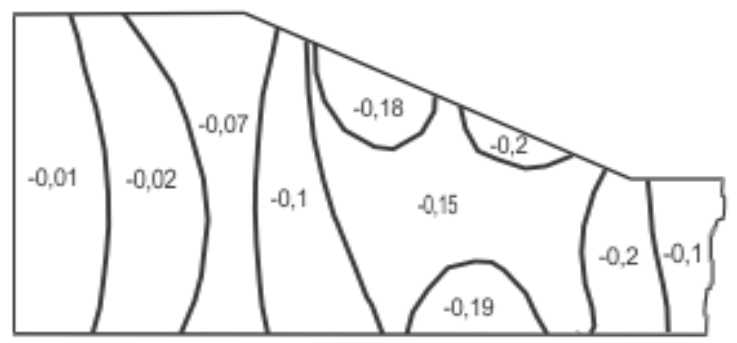

c)

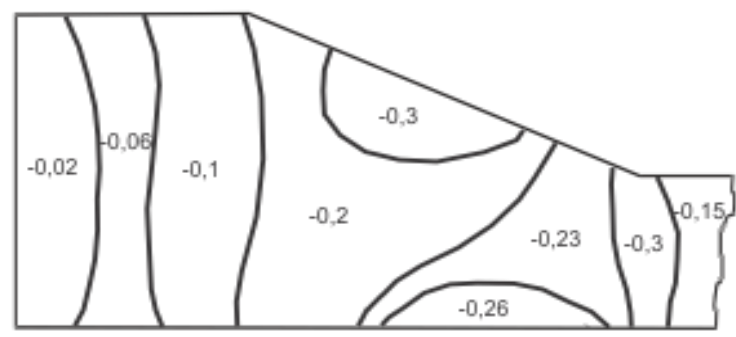

d)

Fig. 3. Radial strain rate $\left(\dot{\varepsilon}_{\mathrm{r}}\right)$ distribution in plastic zone $\left[\mathrm{s}^{-1}\right](\mu=0,05)$ :
a) punch speed $v_{\mathrm{p}}=8 \mathrm{~mm} / \mathrm{s}$
c) punch speed $v_{\mathrm{p}}=16 \mathrm{~mm} / \mathrm{s}$
b) punch speed $v_{\mathrm{p}}=12 \mathrm{~mm} / \mathrm{s}$
d) punch speed $v_{\mathrm{p}}=22 \mathrm{~mm} / \mathrm{s}$

Fig. 4 shows impact of punch speed on the shear strain rate distribution in deformed zone of extruded alloy. It is interesting to note that distribution patterns of strain rates change only little while the change of the values is significant. Especially in the areas around the exit of the forming zone the impact of higher punch speed is enormous. 


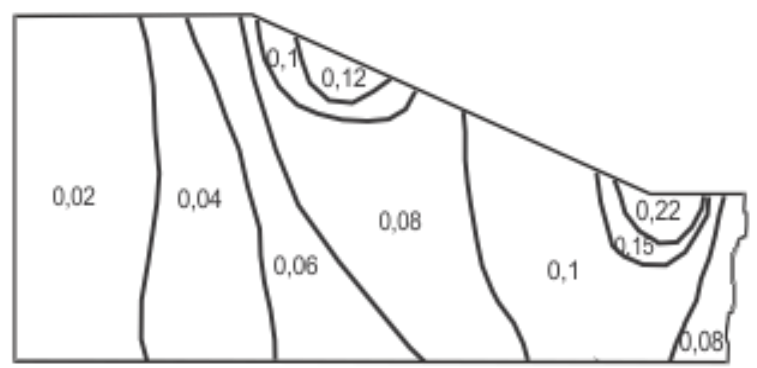

a)

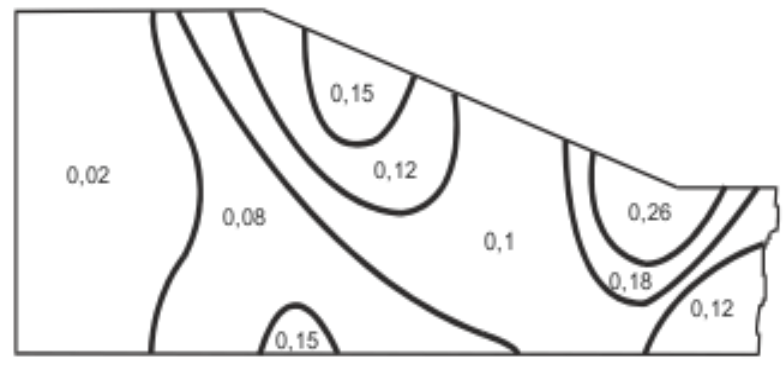

b)

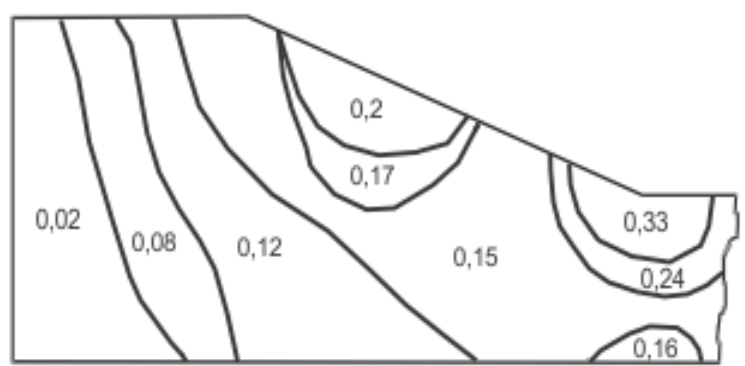

c)

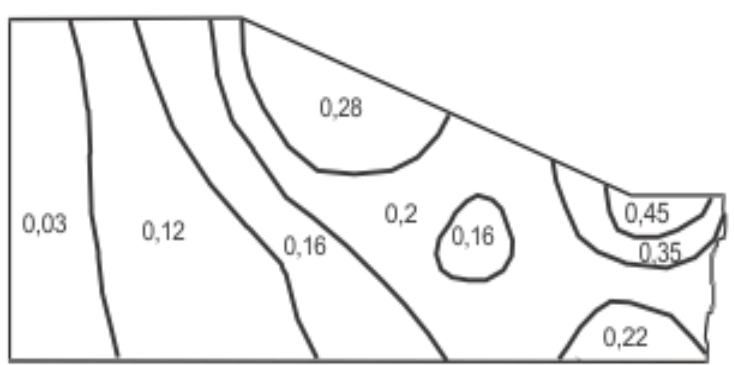

d)

Fig. 4. Shear strain rate $\dot{\varepsilon}_{\mathrm{rz}}$ distribution in plastic zone $\left[\mathrm{s}^{-1}\right](\mu=0,05)$ :
a) punch speed $v_{\mathrm{p}}=8 \mathrm{~mm} / \mathrm{s}$
c) punch speed $v_{\mathrm{p}}=16 \mathrm{~mm} / \mathrm{s}$
b) punch speed $v_{\mathrm{p}}=12 \mathrm{~mm} / \mathrm{s}$
d) punch speed $v_{\mathrm{p}}=22 \mathrm{~mm} / \mathrm{s}$

With maximum punch speed $\left(v_{\mathrm{p}}=22 \mathrm{~mm} / \mathrm{s}\right)$ the highest value of strain rate on the outer zone of the exit of the forming zone reached $\dot{\varepsilon}_{\mathrm{rz}}=0,45$ which is $30 \%$ more when compared to values at $v_{\mathrm{p}}=16 \mathrm{~mm} / \mathrm{s}$. Results for axial and shear strain rate distributions have clearly shown that there are some critical areas with high values in the plastic zone of the extruded material that will also have a great impact on higher stress concentration in those areas.

Based on strain rate distribution analysis only the most interesting areas with the dynamic change of strain rate in deformed zone were selected for radial stress calculation. These selected areas are shown in Fig. 5.

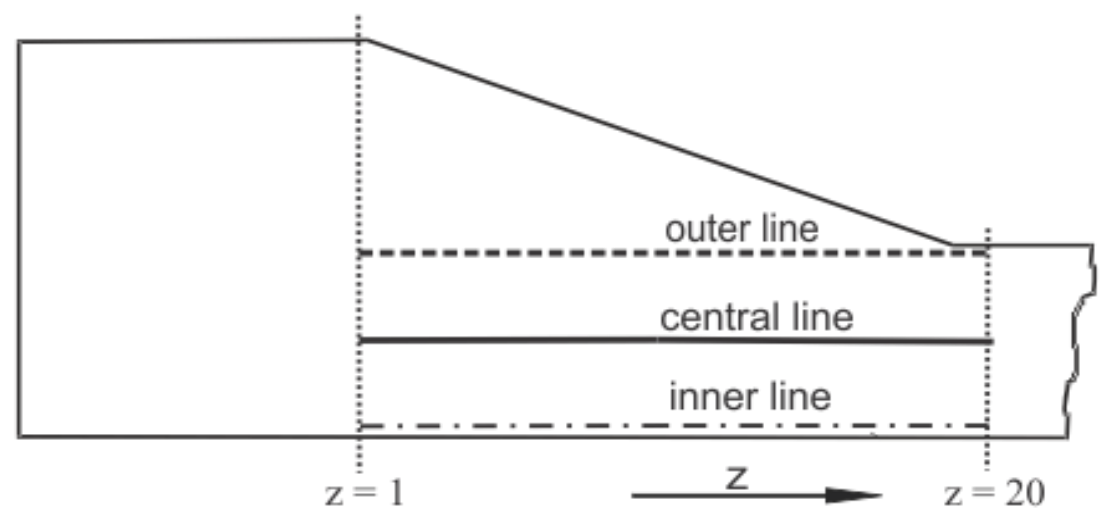

Fig. 5. Measurements area for radial stress distribution in deformed zone. 
On the basis of obtained strain rate components radial stress was calculated according to (9) in 20 points along each of three selected lines in deformed zone, so the total number of mesh points for radial stress calculation was 60 .

The change of the radial stress along selected inner, outer and central line (according to Fig. 5) when lowest and highest punch speed for extrusion process was applied is given in Fig. 6 and Fig. 7. The initial value of flow stress for unformed copper alloy CW106C $\left(\mathbf{s}_{\mathrm{f}}=380 \mathrm{~N} / \mathrm{mm}^{2}\right)$ was obtained by compression test.

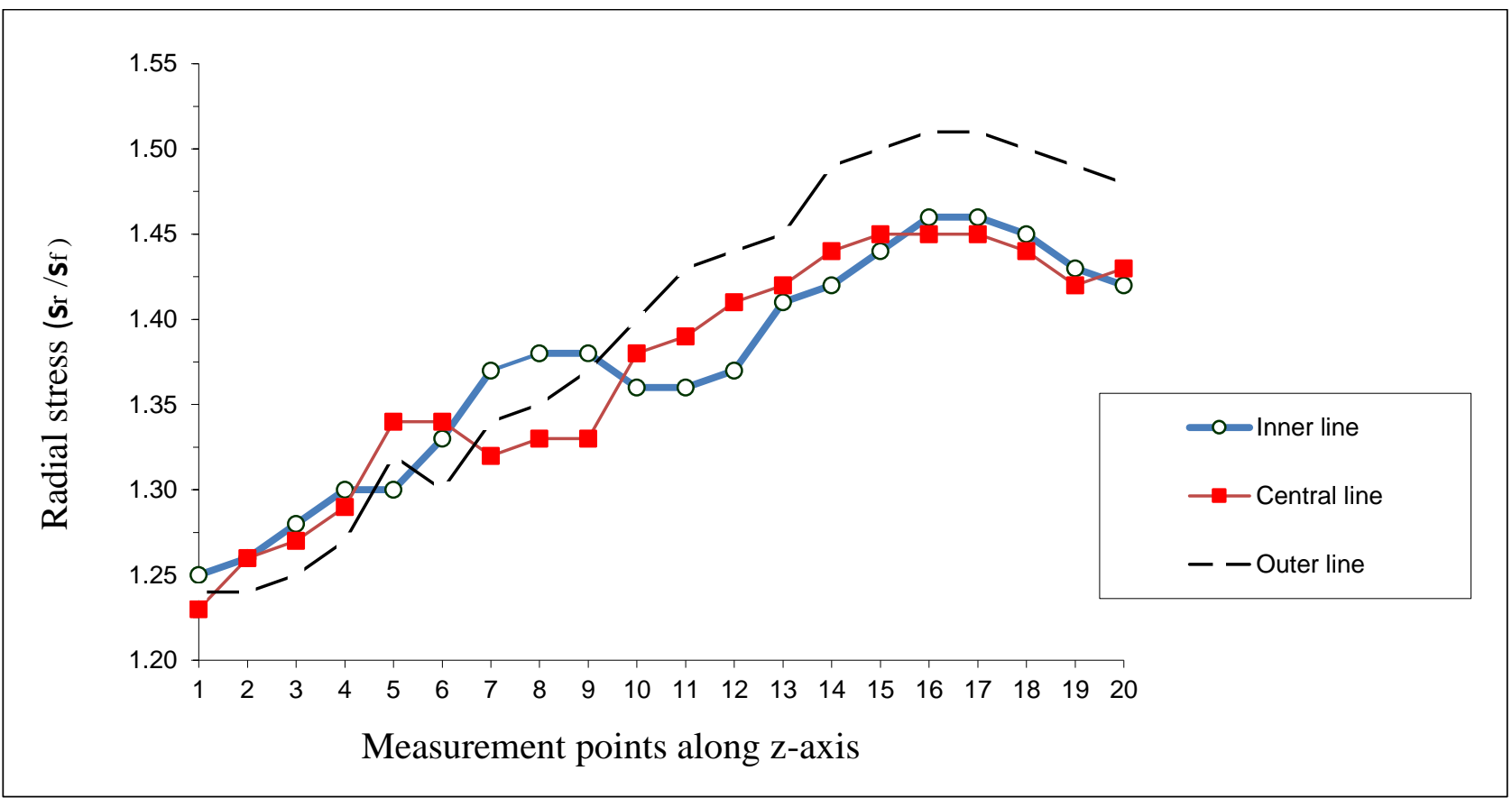

Fig. 6. Radial stress $\left(\mathbf{s}_{\mathrm{r}} / \mathbf{s}_{\mathrm{f}}\right)$ in different areas of deformed zone $\left(v_{\mathrm{p}}=8 \mathrm{~mm} / \mathrm{s}\right)$.

The course of radial stress for three selected areas in plastic zone when punch speed $v_{\mathrm{p}}=8 \mathrm{~mm} / \mathrm{s}$ was applied for extrusion process is presented in Fig. 6. Values for radial stress increase along all three observed lines along $\mathrm{z}$-axis and reach the highest values at the exit of the forming zone. In outer line the maximum radial stress is less than 5\% higher compared to maximum stresses along central and inner lines. The dynamic of radial stress changes is very similar along all three observed areas. The only minor deviation (slightly higher increase than usual) can be observed on the inner line form point $\mathrm{z}=7$ to point $\mathrm{z}=10$.

Fig. 7. shows the change of radial stress distribution in plastic zone when highest punch speed $\left(v_{\mathrm{p}}=22 \mathrm{~mm} / \mathrm{s}\right)$ was used for extrusion. While radial stress along central line increases quite evenly the dynamic of stress change along inner and outer lines is much higher. Especially along inner line large area with highest radial stress values (from $\mathrm{z}=7$ to $\mathrm{z}=12$ ) can be observed. Values in this area are even higher than values reached at the end of the forming zone. This could be due to hindered heat transfer when higher punch speed is applied but also due to some material irregularities in this area. Two critical peak areas with high radial stress concentration occur - one in the middle of central line and one at outer line at the exit of forming zone. Though no cracks were found in those areas it is very likely that with higher punch speed the first cracks would appear in these two critical areas. 


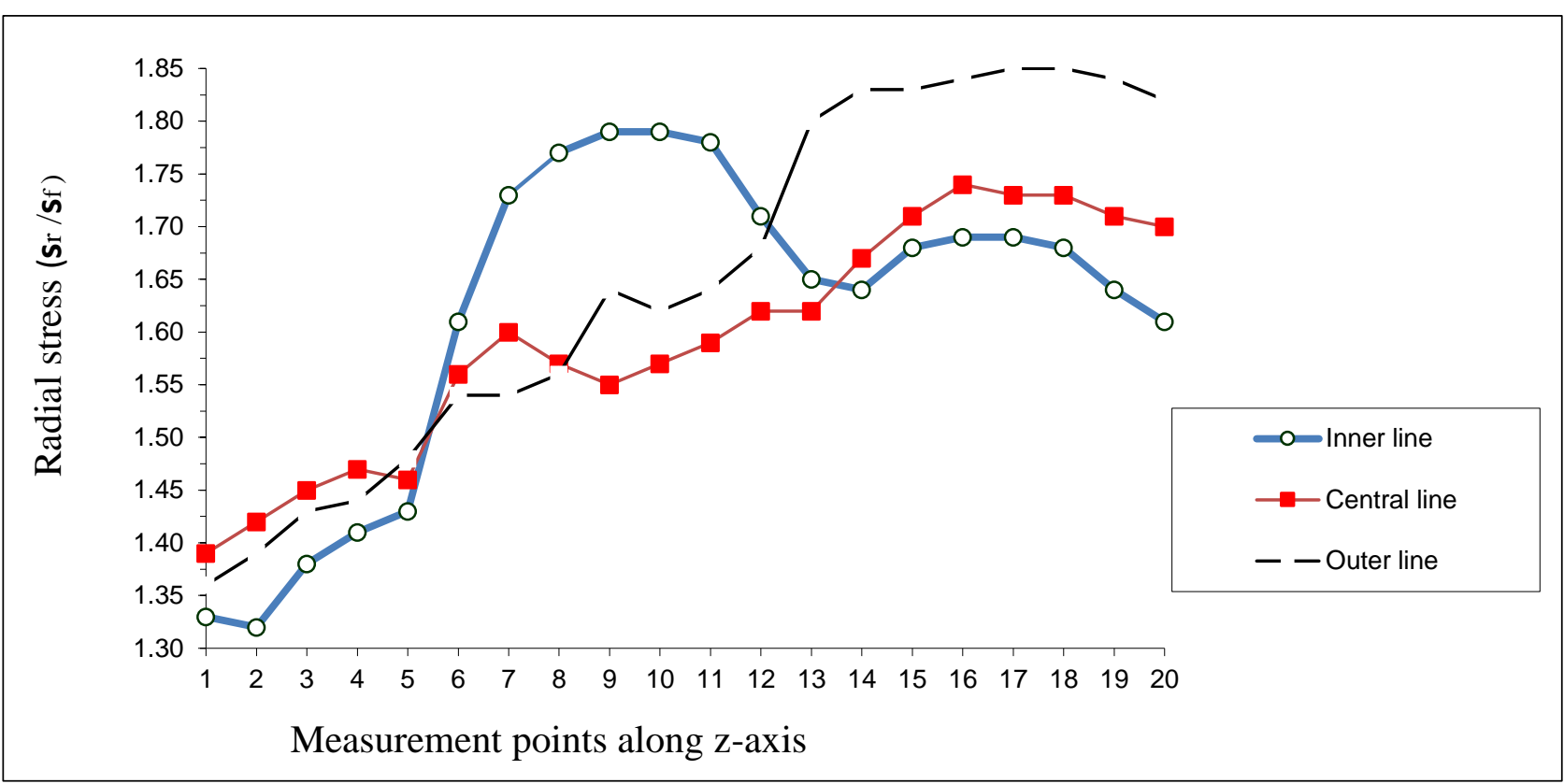

Fig. 7. Radial stress $\left(\mathbf{s}_{\mathbf{r}} / \mathbf{s}_{\mathbf{f}}\right)$ in different areas of deformed zone $\left(v_{\mathrm{p}}=22 \mathrm{~mm} / \mathrm{s}\right)$.

\section{Conclusion}

In mass production processes, such as cold extrusion, sometimes even the smallest improvement of process parameters can result in higher productivity and reduction of production costs. One of these important process parameters is punch speed. In the paper the impact of four different punch speed values on the strain rate and stress distribution in plastic zone of formed CW106C alloy was analyzed by using experimental-analytical visioplasticity method which is very effective method that provides very accurate results. The results have shown great impact of punch speed on strain rate distribution and consequently on stress values in plastic zone of formed material. Significant differences in strain rate and radial stress distribution were obtained along plastic zone. With higher punch speed components of strain rate and stress increase rapidly, especially in some areas at the end of the forming zone and in the middle of extruded specimen where two peaks with the highest stress values were obtained when the highest punch speed was applied. This finding could be of great importance, because these are the critical areas for possible formation of cracks in extruded material. Extruding at a lower punch speed means lower strain rates and stress components and consequently reduction of possible cracks and tool wear while higher punch speeds can significantly increase productivity but on the other hand can cause cracks formation in some critical areas of formed product. In our future work we intend to analyze some additional process parameters with the goal to optimize these parameters for achieving high productivity and high quality products.

\section{References}

Dwivedi, S.; Agnihotri, G. \& Pathak, K. K. (2013). Modelling of metal forming process for simulation process. International Journal of Mechanical and Production Engineering Research and Development, Vol. 3, No. 2, pp. 181-186, ISSN 2249-6890. 
Farhoumand, A. \& Ebrahimi, R. (2016). Experimental investigation and numerical simulation of plastic flow behaviour during forward-backward-radial extrusion process. Progress in Natural Science: Materials International, Vol. 26, No. 6, pp. 650656, ISSN: 1002-0071.

García-Domínguez, A.; Claver, J.; Camacho, A.M. \& Sebastián, M.A. (2015). Comparative Analysis of Extrusion Processes by Finite Element Analysis. 25th DAAAM International Symposium on Intelligent Manufacturing and Automation, Proceedia Engineering, Vol.100, 2015, pp. 74-83, B. Katalinic (Editor), ISSN: 18777058.

Gusel, L. \& Rudolf, R. (2014). Shear stress distribution analysis in cold formed material. Annals of DAAAM 2014, The jubilee 25th DAAAM Symposium, Vienna, Austria, November 2014, Vol. 25, No. 1, pp. 1-5, Katalinic, B. (edit.), ISSN: 23041382.

Ilie, D.E.; O' Donnell, B.P. \& McHugh, P.E. (2007). Computational modelling of the extrusion of an $\mathrm{Al}-\mathrm{SiC}$ metal matrix composite using macroscale and microscale methods. Journal of Strain Analysis for Engineering Design, Vol. 42, No. 4, pp. 237252, ISSN: 0309-3247.

Janjic, M.; Vukcevic, M.; Sibalic, N. \& Savicevic, S. (2016). Load determination by analysing the stress state for the open-die forging of the aluminium alloy AlMgSi0.5. Materials and technology, Vol. 51, No. 3, pp. 463-471, ISSN: 1580-2949.

Jawad, S. K.; Khleif, A. A. \& Abbood, M.Q. (2012). Plane Flow Analysis for a Profile Extrusion Die Using Digital Image Processing Technique. Engineering \& Technology Journal, Vol. 30, No. 9, pp. 1562-1581, ISSN: 1681-6900.

Lange, K. (1994). Handbook of Metal Forming, McGraw Hill Book, New York.

Marin, M.; Nunez, P.; Camacho, A. M. \& Garcia, M. (2013). Comparative of Parameters in the Forging Process by Different Application Load. Chapter 24 in DAAAM International Scientific Book 2013, pp. 449-458, B. Katalinic \& Z. Tekic (Eds.), Published by DAAAM International, ISBN 978-3-901509-94-0, ISSN 17269687, Vienna, Austria, DOI: 10.2507/daaam.scibook.2013.24

Ojo, S.O.; Erinosho, M. \& Ajiboye, J.S. (2015). Experimental Analysis for Lubricant and Punch Selection in Shear Extrusion of Aa-6063. Journal of material science and engineering, Vol. 4, No. 4, pp. 1-5, ISSN: 2169-0022.

Raja Satish, D.; Ravi Kumar, D. \& Merklein, M. (2017). Effect of temperature and punch speed on forming limit strains of AA5182 alloy in warm forming and improvement in failure prediction in finite element analysis. Journal of Strain Analysis for Engineering Design, Vol. 52, No. 4, pp. 258-273, ISSN: 0309-3247.

Tolcha, M.A. (2014). Modelling Plastic Deformation of A36 Mild Steel Under Extrusion Process. International Journal of Engineering Research \& Technology, Vol. 3, No. 7, pp. 1551-1555, ISSN:2278-0181.

Trzepiecinski, T.; Lemu, H. G. \& Fejkiel, R. (2017). Numerical Simulation of Effect of Friction Directionality on Forming of Anisotropic Sheets. International Journal of Simulation Modelling, Vol. 16, No. 4, pp. 590-602, ISSN 1726-4529.

Wang, J.P.; Wang, J.J. \& Tsai, Y.H. (1997). The dynamic analysis of visioplasticity for the plane upsetting process by the flow-function elemental technique. Journal of Materials Processing Technology, Vol 63, No. 1-3, pp. 738-743, ISSN: 0924-0136. 